\title{
The Psychosocial Risks in Workplace as a Category in Research. Comparative Diagnosis
}

\author{
Monika Budnik \\ WSB University, Wroclaw, Poland \\ Email: monika.budnik@wsb.wroclaw.pl
}

How to cite this paper: Budnik, M. (2019) The Psychosocial Risks in Workplace as a Category in Research. Comparative Diagnosis. Open Journal of Social Sciences, 6, 42-52.

https://doi.org/10.4236/jss.2019.72004

Received: November 8, 2018

Accepted: January 29, 2019

Published: February 2, 2019

Copyright $\odot 2019$ by author(s) and Scientific Research Publishing Inc. This work is licensed under the Creative Commons Attribution International License (CC BY 4.0).

http://creativecommons.org/licenses/by/4.0/

(c) (i) Open Access

\begin{abstract}
Article presents the issue of psychosocial risks from perspective diversity on culture context. This context is socially appointed through the meanings by using and conceptualization notions, legitimizing these concepts of notion in the law and through studying phenomena through tools to adequately measure the scale of occurrence of a given psychosocial threat. The main idea of this article focuses on the social constructing concepts and definitions reproduced in the society through: using the notion of psychosocial hazards, different methods and research techniques in the social sciences themselves to explore these phenomena, the different scale of the declared occurrence of social threats to the culturally diverse dimensions of national cultures. Presented areas of psychosocial risks from European perspective, contain differentiated standards which are used in theory and research. Moreover the short article presents the diverse needs of measurement methods adequate for the broad frameworks of psychosocial risks such as mobbing, harcèlement moral, stress and presenteeism.
\end{abstract}

\section{Keywords}

Psychosocial Risks, Tools for Research, Culture Context, Norms, Constructing Meaning

\section{Introduction}

The bipolaties image of work is a symbol-negatives and positives impacts which the work brings to life of man. Psychosocial risks in the workplace are diagnosed in the two paradigms. The first of them presents hazards at work, from the perspective of obligation which is to ensure safety and health in work. The second paradigm explains and describes psychosocial risks in the mainstream from the psychological and sociological perspective. Both currents are present in 
the professional life of man.

Both paradigms indicate areas of life in organization: legal, technical, organizational, psychological and social. Those are potential fields of risk for loss of health at work or lower quality of life affecting hazards on the human health (social, physical and mental).

Differentiation of psychosocial risks is expressed not only by a typology of hazard in the workplace. Areas of differentiation among psychosocial risks are present in the European labor market, in the notion and definition psychosocial risks and also measurement tools used by research in process diagnosis of all types of hazards in the workplace. These elements ultimately affect the image of the phenomenon which is presented in society. Finally the level of awareness of the occurrence, the hazards in society, had derived from the range of information about this phenomenon. Thus, the lack of standard conducting a research about psychosocial risks in politics of national research in the workplace is consent to belittling the role of these hazards in the work process.

In the European statistics (EUROSTAT), we can see the picture of "health at work" interpreted by indicators and values. In statistics, the image "safety and hygiene at work" fills in data: accidents at work, statistics on occupational diseases. Second point of view is subjective perception of working conditions which are measured in a European opinion poll on occupational safety and well being. Nowadays either we give meaning to social issues or this meaning is created by the trade unions as a group for the formation of significant constructs, including concepts such as psychosocial risks. Article [1] refers to this phenomenon of how the notion is created and will be an impulsion for the worker to change their professional group. Not only does Loriol develop the notion of health at work in cases of stress at work but he also creates necessary implementation of a process of intervention at work-focused on the person-for an increased quality of work in the perspective of human relations. In this method, using mindfulness in the workplace helps to develop skills with more freedom from thinking patterns which are based on our dogma in work conflicts [2]. Also Loriol, as well as other authors, refers to the issue by setting a meaning of notion to terms such as health at work or "psychosocial risks" present in surroundings management.

\section{Psychosocial Risk-Frame of Definition}

\section{Frame of Definition}

The concept of psychosocial risk develops with new threats that appear in varying working conditions. According to $40 \%$ of European managers, psychosocial risks are more difficult to manage than traditional security threats and health. Both the paradigm of safety and health in work and also current of psycho-sociological indicate that psychosocial risks arise from human and organizational factors which relate to a human workplace [3].

The International Labour Organization (ILO) complements this definition, 
together with new knowledge about the psychosocial risks. In 1986 psychosocial risk had been defined as "in terms of their interactions among job content, work organisation and management, and other environmental and organisational conditions, on the one hand; and, on the other hand, worker's competencies and needs on the other" [4].

Today's definition of psychosocial risks is expanded by WHO-World Health Organizations which defines it as:

"Psychosocial factors mean a combination of psychological and social variables. These are social, cultural or environmental influences affecting health and behavior of individuals. Examples of psychosocial factors used in this review include social support, social networks, social integration, loneliness, social capital, bereavement, social disruption, work environment, psychological distress, depression, anger and hostility. Psychosocial work environment includes high workload, job demands, strict and tight deadlines, lack of control over work, and imbalance between efforts at work and relevant rewards or job satisfaction" [5]. In relation to the sociological significance of work risks, violence present in relations is a social phenomenon, reproduced in relation. On the basis of this action, forms of control are legitimized in the societies, meanings are given to actions and norms established [6]. In terms from sociology, process the legitimacy of notion in society and creation the state of knowledge creates the reality of a given society [7].

Areas of psychosocial risks in the workplace are defined by contents notion and factors that may impact on the working atmosphere. The content of notion (mobbing or harcèlement moral) in English or French culture context, social norms in law and the scale of social consent or denial of violent behavior in the workplace, the level of knowledge about this phenomenon, creates cultural differences in the perception of psychosocial hazards. The factors this hazards that make up the atmosphere in the workplace are divided on: individual, situational, organizational and social factors. This typology is used in the categorization of research questions in the area of psychosocial risks. We can find them in French research ${ }^{1}$ of working conditions (conducted in the framework of public statistics. The set of factors constructing the atmosphere in the workplace include the following areas.

1) Relation with co-workers

2) Conflicts of values

3) Intensity of work and working time

4) Emotional requirements

5) Autonomy

6) Insecurity of the work situation

These areas of employee relations are closely related to the interaction humans on each other during operation. Sense of safety or pressures of superiors,

${ }^{1}$ Facteurs de risques psychosociaux en France et en Europe, Eurofound, enquête européenne sur les conditions de travail, France, Dares Analyses, Decembre 2014, No 100, access: http://www.travail-emploi.gouv.fr [09. 20.2015]. 
colleagues, or both at the same time this tension, which in combination with verbal violence expressed in gossip, the hurtful of comments it is form of "violence insidieuse" [8].

In relation to the above definition of risk which worker may experience in working life have their roots in aggression, violence and stress. The stress is often a final effect when workers fear the consequences aggression and the violence in interpersonal relationships which experience on both the organization and team atmosphere. Medical and psychological consequences from suffered all type of psycho-social hazards for humans are considered interdisciplinary: in medicine, psychology, sociology and management. In the European studies exactly it-stress and diagnoses its occurrence is the dominant category research among other psychosocial risks. Social and employers interests of diagnosing the psychosocial risks have a direct connection with the economic costs, which are identified with: compensation, leave employees unfit for work, early death, early retirement, medical expenses, court costs, presentism phenomenon [9]. A long-term depression as a social cost arising from work which confirm data Agency for Health and Consumers, European Comission 2013 amounts €617 billion by year for 27 EU-country ${ }^{2}$. From local data as reported Trontin in 2010 on France, costs of job strain in France based on the findings of epidemiological studies including data for the prevalence of cardiovascular diseases, mental disorders and musculoskeletal problems. The job strain was then multiplied by various types of costs, including health care, absenteeism loss of activity and loss of productivity due to premature death. The total cost of job strain was estimated at $€ 1.9$ to $€ 3$ billion in 2007.

\section{Cultural Diversity in Definitions and Research Approaches in Relations with Psychosocial Risks}

The area of psychosocial risks it is sphere of phenomenon which are fed a sense of pressure and violence present in professional life and working in team. The process identifying psychosocial risks are legitimized by the labor codes along with the implementation of these definitions by law. The cultural diversity are create by the whole culture aspects what confirmed the Richard's McKeon concept aspects of culture: "All forms of human behavior may therefore be described in terms of the ways of life and the patterns of conduct valued by groups; political institutions, art forms, religions, and philosophies no less than the organization of the family, the divisions of labor and function, and the forms of domestic utensils enter into the description of such ways of life" [10]. The postmodern concept of culture diversity, underlines the aspects meanings, differen-

${ }^{2}$ Economic analysis of workplace mental health promotion and mental disorder prevention programme and of their potential contribution to EU health, social and economic policy objectives, Executive Agency for Health and Consumers, Final Report Matrix, Specific Request EAHC/2011/Health/19 for the Implementation of Framework Contract EAHC/2010/Health/01 Lot 2 Economic analysis of workplace mental health promotion and mental disorder prevention programmes and of their potential contribution to EU health, social and economic policy objective, 2013, p.35. 
tiation culture in changing world and aspects constructing culture by themselves participants [11].

Among the psychosocial risks we find the phenomenon which are present in different cultural contexts and meaning of definition. In aggregation the notion from literature describe psychosocial risks in Europe and Asia we can meet: harassment, bullying, maltrato psicológico, harcèlement moral, mobbing, Ijima [12], karoshi [13]. All terms although variably translated expresses opressure on the man. Both the definition of these concepts and understanding them from the context native culture in foreign research is a barrier if we look at it through the prism of sociolinguistics. The British perspective in research utilizing the term "bullying" or "mobbing" next to a French native definition this phenomenon harcèlement moral are an example of the diversified linguistic landscape defining risks in different cultures. Cultural context also includes a set of legal sanctions that legitimize the notion in the legal system of the country. Diversified sanctions in national laws in countries which are members of the European Union and the types of legal sanctions are expressing the degree of society knowledge with the issue of bullying as psychosocial risks. Moreover the list of psychosocial risks including such the basic phenomenon as: stress at work and all the causes work stress coming from the content of work and context of workplace. From poor work organizations to monotonus job, working under time pressures, lack of control or lack of participation all of them reference to the content of job. Also the context of work: job insecurity, unclear role in organization, interpersonal relationships with co-workers could be a source of the stress. This all variables refer to the effects of work stress in organizations: increasing absenteeism, increasing staff turn-over [14]. Hence the risk of stress is the psychosocial aspect of work and the consequences of attitudes and behavior towards work and co-workers. This aspects interpersonal relations between co-workers is presence not only by the stress environments, reference to the using the power, unequal conditions at work relations inherent part of psychosocial risks.

The culturally different valuing of given factors as stressful is also a research interest in sociology. Variables regarding the work environment, ways of managing the organization and the scale of social consent or standards regarding influencing an employee by creating stressful situations or striving to reduce stress among employees are the differences inscribed in national contexts. The last report European Agency for Safety and Health at Work [15] inform that between eastern European countries and northern European countries, workers reported differently list of factors address as a psychosocial risks. The relationship between the national context and psychosocial risk management in this research was analysis on level organization and barriers inside and the level comparisons between countries and national cultural dimensions. Between organizations in different countries was not found correlation between psychosocial risk management and the mentioning of paperwork or the complexity of legal obligations as a difficulty in addressing safety and health in the organisation. The mention- 
ing of specific barriers to deal with psychosocial risks compared with other health risks was not related to psychosocial risk management. Among the studied variables, which was differentiating employees and management in various countries was analysis lack of awareness among staff and lack of awareness among management. The comparison national context show how the national cultural dimensions (uncertainty avoidance, masculinity and power distance) are related in correlations between the national context variables. In results the cultural dimensions power distance and uncertainty avoidance are strongly associated between the other national context variables. Masculinity is not statistically significantly related to psychosocial risk management. Also in research included GDP per capita, joint efforts of social partners and measures taken to implement the EU framework agreement on work-related stress. Most countries with a favourable cultural context also have a favourable economic situation and favourable national initiatives, and most countries with an unfavourable cultural context also have an unfavourable economic situation and unfavourable national initiatives. However, exceptions do occur. For example, in France GDP is below average and also the cultural context is not favourable for psychosocial risk management.

\subsection{Example of Mobbing and Harcèlement Moral in Law and Content of Notion}

The confirmation of these differences in cultural contexts that contain different law, may be varied sanctions in the Polish and France civil codes. In terms of the penalties provided for employers where will be confirmed case of the occurrence of mobbing or harcèlement moral.

In France, as well as in Poland, the precision for these official expressions for the psychosocial risks, like mobbing and harcèlements moral, is determined through the Labor Code and Penal Code.

Harcèlements moral is addressed in the French Labor $\operatorname{Code}^{3}$ (Title 5, chapter II, Article L1152-1 - L1152-6) as follows: "No employee should be subjected to repeated acts of harassment, which aim at, or result in a deterioration of working conditions, which can violate an employee's rights and dignity, have a negative effect on physical and psychological health or jeopardize his career".

In the Polish Labor Code (Art. $94^{3} \$ 2$.), the expression mobbing is defined as a phenomenon that involves "actions or behavior toward an individual or directed against an individual, involving harassment and intimidation of an individual, occurring on a frequent basis and over a very long time, resulting in decreased evaluation of professional capabilities, aiming to humiliate or ridicule an individual, isolate or force an individual out of the workplace".

The differences of the Polish and French Labor Code in terms of the two expressions, despite current European guidelines, vary in terms of the types of imposed sanctions. The forms of sanctions, that are catalogued in the French Penal

${ }^{3}$ French Labor Code consolidated version from 1 January 2016

[Access: http://www.legifrance.gouv.fr (01.08.2015)]. 
Code for perpetrators of harcèlements moral, extend the Polish sanctions. They indicate the maximum fine of 30,000 EUR that may be imposed in cases of proven acts of harassment and up to two years of imprisonment ${ }^{4}$. The Polish judicial system does not specify a potential length of incarceration, as well as the amount of potential monetary compensation in any schedule of charges.

Methodological tools in the area of social research, used in the practice of European companies in the subject of measure psychosocial risk fulfill two functions. The Preventive function implemented in order to monitor risks in the workplace. The second function of the use of research in enterprise, the function of minimizing the economic costs which pose a psychosocial risk. Therefore, the estimation of risks and their costs it is important in management.

\subsection{Example of Mobbing and Harcèlement Moral in Context Tools Using in Methodology in Social Science}

The last function which is explanation, descriptive studies of psychosocial risks meets the public statistics and public institutions performing tasks in the field of monitoring work conditions. This applies especially to research conducted and funded by the European Union agencies and national, local institutions that perform public tasks in monitoring psychosocial risks associated with the work. Tools to measure different types of psychosocial risks, focusing on the diagnosis of the factors are indirect costs incurred by the employer. That cost it is: presenteeism as a presence at work in spite of illness or working by through many hours where efficiency falls. Presenteeism related with absenteeism resulting from work pressures or stress before returning to work or prolonged absence in work. Some from the psychosocial risks in the calculation of indirect costs of require statistical calculations using formulas. The other hand we can diagnose the presence of the same phenomenon by declarations of employees using questionnaires to diagnose the presence of certain phenomena in the organization or the frequency of their occurrence. Tools based on the use of questionnaires in social studies are a form possible to use in enterprise among employees. In the case of diagnosing the presence presentism we can make it using research tools such as questionnaires Stanford Presenteeism Scale-SPS 6 [16]. This questionnaire with six questions diagnoses the relationship of stress with symptoms of somatic health by declaration of the respondent in the last month of work. Originally, the questionnaire used in the United States at Stanford University, now is also used in Europe ${ }^{5}$.

The second type of tool for Presentism, questionnaire measurement labor productivity initiated by the World Health Organization (WHO) called by Ronald C. Kessler [17] the Health and Work Performance Questionnaire- $\mathrm{HPQ}^{6}$. The difference between these tools it is options questionnaire for the employee and the employer-it is in HPQ, whereas the SPS-6 questionnaire is dedicated 
only to employees. The second area of differentiation it is quantity of survey questions and the field of work about which we ask. Different is also the period in respect of which the respondent refers own declaration. In the case of the questionnaire HPQ respondent is asked about answer from time filling the questionnaire and also the experience of the last four weeks or two years back from the date of the filling the questionnaire. Thus diagnosed wide temporally experience of life respondent by the HPQ questionnaire. Questionnaire SPS-6 with six questions directed to employee diagnosed workers experience of the last month. Among the psychosocial risks relating to work relationships is also mobbing. This phenomenon functioning under different terms in different culturally surroundings. In France is being used term harcèlément moral identified as behavior vengeful, malicious, present in workplace against an individual or group of people. Measurement experiencing harassment by employees of research has its limitations. How can you measure the experience of mobbing in the workplace? You can choose the method of sham, exploring phenomenon at the level of declarations. They are just a stopgap of research. If respondent does not identify the kind of behavior with the definite phenomenon this lack of knowledge translates to on answers. Moreover, irritability of this phenomenon raises concerns of respondents. Regardless of cultural contexts, we distinguished measurement tools which have variable of recognition among researchers from different cultural contexts.

Culturally different are also adaptations of research tools. Scandinavian and British experience, resulted in two patterns of research tools to diagnose of mobbing. On example psychosocial phenomenon referring by two methods of measuring hazards by such tools as a (LIPT and NQR). The first questionnaire LIPT which is repeatedly used in European research on violence in the workplace is a questionnaire LIPT (Leyman Inventory Psychological Terrorisation) from 1990 [18], The second questionnaire named Negative Acts Questionnaire-Revised (NAQ-R) [19], which as an instrument of measurement focuses on the frequency and intensity of harassment at work and victimization in the workplace. The tool NAQ created in 2000, repeatedly tested by the Bergen Bullying Research Group in the University in Bergen, Norway (International Database on the Prevalence and risk factors of bullying at work, abbreviation IDPB), they gathered over 60 studies and more than 40,000 respondents from about 40 countries in the IDPB ${ }^{7}$. Table 1 presents a comparison of tools.

\section{Conclusions}

The main purpose of this article was to show the frame of diversity in theme psychosocial risks as a category of research. Presented differences by the cases, indicate how the legitimization process is done through social formation of notion mobbing and harcèlement moral. By the norms, values and social practice, the national cultures give the recognition and reproduce the meaning violence in the workplace.

7access: http://www.uib.no. 
Table 1. The following table indicates the characteristics of both research tools. Self study based on Einarsen et al. 2009, Leymann 1990.

\begin{tabular}{|c|c|c|}
\hline Instrument & $\begin{array}{l}\text { Leyman Inventory Psychological } \\
\text { Terrorisation (LIPT) }\end{array}$ & $\begin{array}{l}\text { Negative Acts Questionnaire-Revised } \\
\text { (NAQ-R) }\end{array}$ \\
\hline $\begin{array}{l}\text { What is the main } \\
\text { goal of the study? }\end{array}$ & $\begin{array}{l}\text { Incident reports }(\mathrm{s}) / \mathrm{absence} \text { of } \\
\text { violence in the workplace }\end{array}$ & Incident Frequency Measurements \\
\hline $\begin{array}{l}\text { Field of } \\
\text { exploration }\end{array}$ & $\begin{array}{l}\text { The questions cover the six areas of } \\
\text { workplace ambience: } \\
\text { 1) Sphere of communication } \\
\text { 2) Sphere of social relations } \\
\text { 3) Sphere of damage to a person's } \\
\text { reputation } \\
\text { 4) Sphere of encroachment on } \\
\text { autonomy } \\
\text { 5) Sphere immediate criticism or } \\
\text { intermediary. } \\
\text { 6) Sphere of threats of sexual assault }\end{array}$ & $\begin{array}{l}\text { Questions relate to the three areas of the } \\
\text { workplace ambience: } \\
\text { 1) Personal harassment/bullying* } \\
\text { 2) Work-related harassment } \\
\text { 3) Forms of bullying/bullying by physical } \\
\text { intimidation } \\
\text { * originally term bullying used by } \\
\text { Norwegians using this tool }\end{array}$ \\
\hline $\begin{array}{l}\text { The frequency } \\
\text { of violence } \\
\text { experienced as } \\
\text { a condition of } \\
\text { recognition that } \\
\text { the person has } \\
\text { been subjected } \\
\text { to violence. }\end{array}$ & $\begin{array}{l}\text { At least one negative effect, } \\
\text { repeated at least once a week and } \\
\text { continuing for at least six months. }\end{array}$ & $\begin{array}{l}\text { A single incident in six months is not } \\
\text { considered bullying. }\end{array}$ \\
\hline $\begin{array}{l}\text { Number of } \\
\text { questions }\end{array}$ & $\begin{array}{l}\text { Number of questions in } \\
\text { the questionnaire } 45 \text { questions } \\
\text { in the original version. }\end{array}$ & $\begin{array}{l}23 \text { questions in the original } \\
\text { Scandinavian and British version. }\end{array}$ \\
\hline
\end{tabular}

Indirectly it is information about level of knowledge in this type of hazards in society. The fact that not every country EU-27 implemented diagnosis about psychosocial risks in national statistics shows deficits in this area of European research and standarization in European research working conditions. Image of psychosocial risks is determined by the definition, depth diagnosis of the problem and a research tool. That affects the final image which the researcher presents to the reader.

Recalling the cases in this article indicated symbolic differences in the national dimensions of culture, in certain areas that interpret psychosocial hazards differently but recognize their harmfulness together. These all show difference degree of social acceptance of psychosocial risks in the workplace.

\section{Conflicts of Interest}

The author declares no conflicts of interest regarding the publication of this paper.

\section{References}

[1] Loriol, M. (2015) La souffrance au travail: Construction de la catégorie et mise en forme de l'expérience. Pensée Plurielle, 38, 23-33.

https://halshs.archives-ouvertes.fr/halshs-01236165 
https://doi.org/10.3917/pp.038.0023

[2] Loriol, M. (2014) Approches constructivistes des RPS. In: Zawieja, P. and Guarnieri, F., Dictionnaire des risques psycho-sociaux, Paris, éditions du Seuil, 52-55.

[3] Hassard, J., Teoh, K., Cox, T., Dewe, P., Cosmar, M., Gründler, R., Flemming, D. and Milczarek, M. (2014) Calculating the Cost of Work-Related Stress and Psychosocial Risks. European Risk Observatory, Literature Review European Agency for Safety and Health at Work-EU-OSHA, Luxembourg, 4.

https://osha.europa.eu/en/tools-and-publications/publications/literature_reviews/ca lculating-the-cost-of-work-related-stress-and-psychosocial-risks

[4] Kudasz, F. and Hupke, M. (2015) Psychosocial, Risks and Workers Health, Networking Knowledge. European Agency for Safety and Health at Work.

http://www.oshwiki.eu

[5] Pikhart, H. and Pikhartowa, J. (2015) Health Evidence Network Synthesis Report, The Relationship between Psychosocial Risk Factors and Health Outcomes of Chronic Diseases: A Review of the Evidence for Cancer and Cardiovascular Diseases. WHO Europe, 10. http://www.euro.who.int

[6] Hartmann, E. (2017) Violence: Constructing an Emerging Field of Sociology. International Journal of Conflict and Violence, Potsdam University, 11.

[7] Berger, P.L. and Luckmann, T. (1966) The Social Construction of Reality. A Treatise in the Sociology of Knowledge. Penguin Books, England, 26-27.

[8] Dressen, M. (2011) Violences dans le travail, esquisse d'une typologie. In: Dressen, M. and Durand, J.P., Eds., La violence au travail, collection: Le travail en débats, série colloques et congrès, Toulouse, Octarès, 373-380.

[9] Johns, G. (2010) Presenteeism in the Workplace: A Review and Research Agenda, Journal of Organizational Behavior, 31, 519-542. https://doi.org/10.1002/job.630

[10] McKeon, R. (1950) Philosophy and the Diversity of Cultures. Ethics. An International Journal of Social, Political and Legal Philosophy, LX, 260. https://doi.org/10.1086/290731

[11] Griswold, W. (2013) Cultures and Societies in a Changing World. Sage, USA.

[12] Kiyoko, A. and Henly, S.J. (2010) Bullying (Ijime) among Japanese Hospital Nurses Modeling Responses to the Revised Negative Acts Questionnaire. Nursing Research, 59, 110-118. https://doi.org/10.1097/NNR.0b013e3181d1a709

[13] Li, J. (2016) Karoshi: An International Work-Related Hazard? International Journal of Cardiology, 206, 139-140. https://doi.org/10.1016/j.ijcard.2016.01.092

[14] Stravoula, L., Amand, G. and Cox, T. (2005) Work Organization and Stress. Protecting Workers Health, World Health Organizations, Great Britain, 5-7.

http://www.who.int/occupational_health/publications/pwh3rev.pdf

[15] Milczarek, M. (2018) Management of Psychosocial Risks in European Workplaces-Evidence from the Second European Survey of Enterprises on New and Emerging Risks (ESENER-2). European Agency for Safety and Health at Work, Luxembourg, 30-59.

[16] Koopman, C., Pelletier, K.R., Murray, J.F., Sharda, C.E., Berger, M.L., Turpin, R.S., Hackleman, P., Gibson, P., Holmes, D.M. and Bendel, T. (2002) Stanford Presenteeism Scale: Health Status and Employee Productivity. Journal of Occupational and Environmental Medicine, 44, 14-20. https://doi.org/10.1097/00043764-200201000-00004

[17] Kessler, R.C., Barber, C., Beck, A., et al. (2003) The World Health Organization and Work Performance Questionnaire (HPQ). Journal of Occupational and Environ- 
mental Medicine, 45, 156-174. https://doi.org/10.1097/01.jom.0000052967.43131.51

[18] Leymann, H. (1990) Mobbing and Psychological Terror at Workplaces. Violence and Victims, 5, 119-126. https://doi.org/10.1891/0886-6708.5.2.119

[19] Einarsen, S., Hoel, H. and Notelaers, G. (2009) Measuring Exposure to Bullying and Harassment at Work: Validity, Factor Structure and Psychometric Properties of the Negative Acts Questionnaire-Revised. Work \& Stress, 23, 24-44.

https://doi.org/10.1080/02678370902815673 